\title{
Synthesis of methods and principles of ensuring the reliability of one-off and serial production machines
}

\author{
Valery Kasyanov ${ }^{1}$, Viktor Deryushev ${ }^{1}$, Evgeny Kosenko ${ }^{1, *}$, Vera Kosenko ${ }^{1}$, and Alina Y. \\ Golubeva $^{2}$ \\ ${ }^{1}$ Don State Technical University, The Faculty of Road-Transport, Russia \\ ${ }^{2}$ Don State Technical University, The Faculty of Civil Engineering, Russia
}

\begin{abstract}
The paper considers the development of methods for managing the reliability of single-production machines (lunar rover, rover, rolling mill, president's car of the country, etc.). Many years of experience in the field of machine reliability allowed the leading specialists of the department of AS and DS to develop a method for managing reliability for serial and mass machines. in the case of evaluating the reliability of singleproduction machines, development of algorithms based on sample data and data obtained during the transition from the sample to the set of values was carried out. The resource of the parts is defined as the main parameter, which, irrespective of their purpose, form the sampled samples of units of finite volume. Given that the main parameter of the details - the resource depends on the strength and loading parameters, the correlation between the strength parameters and the acting stresses (endurance limit, active stress in the dangerous section, strength increase coefficients and the coefficient of increasing the acting voltage) is used in the studies. In such conditions, the estimated resource should relate to each entity of the population or a sample from it. During the research, a parameter is defined as the minimum resource that will determine the homogeneity of the sample (the aggregate), while the main condition for ensuring the same main parameters of parts with sudden failures is the Veler-SørensenKogayev formula based on the experimental initial fatigue and loading statistics. Thus, a method has been developed to ensure the reliability of single-source machines, based on the synthesis of two methods and principles for serial and single-purpose machines.
\end{abstract}

\section{Introduction}

The development of control mode of parts reliability, assembly units and one-off production machines (lunar rover, rover, rolling mill, president's car, etc.) is of great importance in contrast to serial machines (the production volume of thousands and even millions of units), if available for sampling and a set of statistical information on failures, repairs and maintenance [1].

\footnotetext{
* Corresponding author: a123lok@mail.ru
} 
Experience gained for the last 50 years - since 1968, including our department of the Car and Construction Service, Hoisting-and-transport machines and equipment department and Technical operation and maintenance of vehicles and equipment department of the Don State Technical University (Rostov Civil Engineering Institute) together with the scientific laboratory of controlling the reliability of machines in this department and on the basis of the first GOST on terms in the field reliability of equipment (about 50-60 GOSTs) allowed to create a control mode reliability method for serial and mass machines.

However, for one-off production machines, in the absence of sampling and accordingly statistical information, these GOSTs could not be used. Therefore, undertaking research into the development of methods and ensuring the reliability of one-off production machines principles is topical.

\section{Formulation of research tasks}

The tasks within this scientific problem are:

- undertaking research to justify ensuring the reliability of one-off production machines principles;

- characteristic the phases of ensuring reliability at the stage of design, manufacture and operation of one-off production machines;

- development of guidance documents and standards of the Russian Federation on system maintenance of reliability of one-off production machines;

- development of a set of GOSTs of the Russian Federation for the provision of one-off production machines.

\section{The development of the process of ensuring the reliability of one-off production machines.}

The scientific novelty of this research is to develop a method of a system reliability of oneoff production machines with the use of new statistical information in the presence of $1-2$ machines, but approximately the same information from one, two serial production machines (sample $\mathrm{n}=10-50$ and 100).

If the sample representativeness is its main quality, then another sample quality homogeneity was not used. The sample homogeneity is its property, which consists in the equality (with a given error) of the main parameters of the sample selection [2].

We will consider the resource of the part (regardless of its purpose: shaft, pinion, bearing, etc.) as a main parameter. At that case different purposes parts from gearbox, engine, brake system, etc. make samples for example: 20, 40 or 75 parts. In this case, a machine of 3-10 thousand parts is a combination of a final volume, and any node (assembly unit) is a sample from this set.

The main parameter of the part is a resource of Trpi depends on the strength parameters, the loading, i.e. factors increasing or decreasing the strength and acting stresses and others:

$$
\text { Trpi }=f(\sigma-1 p, \sigma a, \beta, \kappa),
$$

where $\sigma-1 p$ - limit of parts endurance;

$\sigma a-$ acting stresses in a dangerous section of the part;

$\beta$-rate of increase of the part strength;

$\kappa-$ rate of increase of acting stresses

It is essential that this design life with an acceptable margin of error is applied to each object of aggregate or sample from it (Fig.1) [3-5]. 


\section{PARTS}

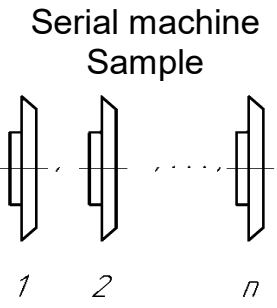

One-off production machine Sample

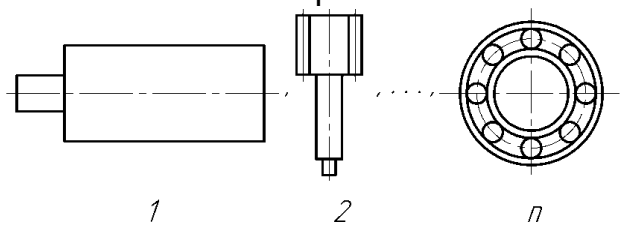

Identical parts (pinions) by purpose and main parameter Trpi

Identical parts on the main parameter, but different in purpose

Fig. 1. Examples for machine parts.

Thus, the different purposes parts (shafts, pinions, chains, etc.), but with the same resource constitute a homogeneous aggregate and sample from it.

However as a basic parameter should be used minimum component life.

Then the sample homogeneity (aggregate) will be determined in the same minimal component life TrpiMIN:

$$
T_{r p i M I N} \approx T_{r p 2 \min } \approx \ldots \approx T_{r p n M I N} \approx T_{\text {rap }}
$$

where Tarp - assigned resource to part's limit state.

The main condition to ensure the same main parameters of the parts with the sudden failure of the resource Trpi (one-off production machines) is a Veller-Serensen-Kagaev on experimental statistics of original fatigue strength and loading.

In the presence of probabilistic distributions of sampling parameters $\sigma-1, \sigma a, \beta, \kappa$ and other, a modeling is done depending on the further transition to the distribution of aggregate and then to find its minimum values for the required parameters [6,7].

Modeling is advisable to perform not for each aggregate part, and for a sample of $n=10$ 100 parts

The analysis of national surveys showed a limited list of publications with 2 articles of Kasyanov V. E. and one thesis for the Candidate's Degree of Kurdyumov S. G.

Attempt to find the world's scientific rivals on the problem of ensuring reliability of one-off production machines showed the lack of related information in the public media.

The entire composition of the machine parts must be divided with account of the effects of parts failures on the machine failure.

As distinct from the serial machines as a rule there aren't samples of the single type parts and nodes for the one-off production machines [8, 9].

However, along with well-known and widely used property of the sample representativeness (representativity), there is another property - homogeneity, which is characterized by the equality of the main parameters of the parts (nodes) such example is the resource $[10,11]$. A method of securing reliability of a one-off production machines is based on a group of principles:

1. A homogeneous sample is formed from parts not according the purpose, but on the main parameter - resource with acceptable error; in the presence of the sample the principles of ensuring reliability of serial production cars are used.

2. Adjacent parts represent a part of the testing workbench; parts of the whole machine form the workbench. 
3. It is advisable to have a backup machine for the period of planned maintenance and application repair and maintenance.

These listed principles for one-off production machines, allow for the first time to introduce the concept of sampling for one or another machine node.

In this case, you can use the experience of collecting and processing the necessary information about the failure, restores (repairs), maintenance, etc., obtained in relation to the serial production machines.

These samples are respectively the nodes of the a one-off production machine when the number of parts in the node is more than 10-20 and constitute for amount the general aggregate of finite volume for such car.

However, if there is a group of principles of ensuring the reliability of the serial machines it is necessary supplementary use the following principles:

1. The totality of the final volume is applied (instead of infinite)

2. The Weibull law is applied for this aggregate without the location parameter; it is replaced by the first minimal value of the order series.

3. Parts of sudden fatigue failures are designed for minimal resource with some margin ensuring absolute reliability for the assigned resource.

\section{Summary}

Thus, according to the results of the synthesis (generation) of considered principles a method of ensuring the reliability of one-off production machines was proposed.

\section{References}

1. Kasyanov V.E., Principles and characteristics of methods to ensure the reliability of machines of a single production, Engineering Herald of the Don, No. 5, , P. 205 (2017)

2. Handbook of probability calculations, (M.: Military Publishing, 1970)

3. Kasyanov V.E., Integral estimation, increase and optimization of reliability of machines (on an example odnokovshovogo excavator), the herald of mechanical engineering, 1990, №4, p.7-8 (1990)

4. Kasyanov V.E., Principles of creating a machine with absolute reliability, Don. VNINITK, January 13 (2014)

5. Kasyanov V.E., Shchulkin L.P., Determination of the gamma-percentage resource of the boom of a single-bucket excavator, Nuchnoe obozrenie, No. 10-2, P. 437-440 (2014)

6. Kasyanov V.E., Shchulkin L.P., Determination of the maximum loading of parts by means of modelling, Nuchnoe obozrenie, No. 10-3, P. 671 - 674 (2014)

7. Kasyanov V.E., Shchulkin L.P., Influence of the volume of the aggregate of the purpose of strength and loading of parts, Nuchnoe obozrenie, No. 11-3, P. $782-784$ (2014)

8. Deryushev V.V., Sidelnikova Ye.G., Structure and model of constructing an integral indicator for assessing the quality of construction and lifting and transport equipment, Scientific review, No. 9, P. 311-313 (2013)

9. Deryushev VV, Sidelnikova Ye.G., The choice of alternative solutions in the presence of risk taking into account uncertainties, Scientific Review, No. 9, P. 325-328 (2013)

10. Kostoglotov A.A., Deryushev V.V., Kostoglotov A.I., Identification of the parameters of dynamical systems on the basis of the combined maximum principle, Izvestiya 
Vysshikh Uchebnykh Zavedenii. North-Caucasian region. Series: Natural Sciences, No. S2, P. 13-18 (2004)

11. Deryushev V.V., Seleznev S.M., Sobisevich A.L., Specific features of the repeated impulse action on resonance systems, Doklady Earth Sciences, T. 369, P. 1176-1178 (1999) 